\title{
Alternative Malaria Diagnostic Tools: Evaluation of Plasmodium falciparum Detection along Thailand's Border by Loop-Mediated Isothermal Amplification (LAMP) and Immunochromatographic Test (ICT)
}

Salakchit Chutipongvivate*, Yongyut Prompunjai, Wanvisa Neadruengsang and Supaporn Wangsiricharoen

Department(s) and institution(s) Regional Medical Sciences Center 6, Department of Medical Sciences, Ministry of Public Health, Thailand

\begin{abstract}
Introduction: Thailand has a national goal to eliminate malaria from 80 percent of the country by 2020. However, malaria-endemic areas still exist along the forested Thailand's borders. An accurate and prompt diagnosis is the key to effective disease management. This aim of this study was to evaluate the application of LAMP as an alternative tool for falciparum malaria diagnosis of clinical suspicion of plasmodium infection in the border area, compared to those of ICT and microscopy using nested PCR as the reference detection method.
\end{abstract}

Materials and Methods: One hundred and four of blood samples were obtained from patients who were diagnosed malaria positive by clinical diagnosis or subjected to suffering from malaria as observed from clinical history. The primer set used for LAMP was designed on the basis of nucleotide sequence of 18S rRNA plasmodium gene and the ICT test was performed with the parasite lactate dehydrogease $(\mathrm{pLDH})$ antigen-based lateral flow test.

Results: The LAMP assay has the highest agreement with the reference method $(99.04 \%, \kappa=0.98)$ with a sensitivity $(95 \% \mathrm{Cl})$ of $98.59 \%(95.85-100.00)$ comparable to ICT and microscopy. Moreover, LAMP showed specificity $100 \%$ compared with $100 \%$ of ICT and $96.97 \%(91.12-100.00 \%)$ microscopy. Negative predictive value of LAMP and ICT were $97.06 \%$ and $82.50 \%$ respectively.

Conclusion: LAMP is useful and more reliable for specific diagnosis in border regions where malaria is endemic but individuals are asymptomatic and hence that LAMP could be the preferred method in resource-limited laboratories to progress towards malaria elimination in Thailand.

Keywords: Loop-mediated isothermal amplification; Immunochromatographic test; Nested polymerase chain reaction

\section{Introduction}

Malaria is an endemic disease which is caused by Plasmodium parasites. There are five parasite species that cause malaria in humans; Plasmodium falciparum, Plasmodium vivax, Plasmodium malariae, Plasmodium ovale and Plasmodium knowlesi [1]. P. falciparum and $P$. vivax are the most common but $P$. falciparum is the most deadly. An accurate and prompt diagnosis is needed to deploy the impact of effective treatment especially for potential fatal cases of $P$. falcifacirum $[2,3]$. Thailand has experienced a 70 percent decrease in reported malaria cases between 2000 and 2011 [4]. Central Thailand has been malaria-free for more than three decades [5]. Therefore, Thailand has a national goal to eliminate malaria from 80 percent of the country by 2020 [6]. However, malaria-endemic areas still exist along the forested Thailand's borders with Myanmar to the west and Cambodia to the east [5]. Several major outbreaks occurred along Thailand's borders [7]. Moreover, the border area has been the epicentre of multidrug resistant P. falcifacirum [8]. The patient's signs and symptoms of malaria are nonspecific and variable [2,9]. Accordingly, differentiation of clinical diagnosis is sometimes difficult and confirmatory diagnosis using laboratory technologies is needed. An accurate parasite-based diagnosis of malaria is essential for proper treatment of individual patients [10].

Conventional laboratory diagnosis has relied on microscopy. It is an accurate tool but requires well-trained staff. Interpretation of smear requires expertise. Recently, the Immunochromatographic test (ICT) have become available, which are based on the recognition of Plasmodium antigen in the blood circulation of patients. The test is rapid and simple. Following WHO recommendation, ICT were used as rapid diagnosis test for malaria infection [11]. More recently, the interpretation of malaria diagnosis and epidemiology has changed by using molecular tools, for instance by revealing grand reservoirs of asymptomatic infection and, by detecting distribution of Plasmodium spp. infection. According to DNA amplification, nested polymerase chain reaction (nested PCR) method targeting 18S rRNA gene, all species could be identified $[12,13]$. However, a major drawback of the molecular detection tool is its cost, requiring PCR machine and welltrained staff. The loop-mediated isothermal amplification (LAMP) is a most recently developed molecular technique that overcome disadvantage of PCR by being simpler and faster. The cost of the technique can be reduced by using a water bath or a heat block instead of PCR [14-16].

The aim of this study was to evaluate the application of LAMP as an alternative tool for falciparum malaria diagnosis of clinical suspicion of plasmodium infection in the Thailand border area, compared to those of ICT using nested PCR as the reference detection method.

${ }^{*}$ Corresponding author: Dr. Salakchit Chutipongvivate, Regional Medical Sciences Center 6, Department of Medical Sciences, Ministry of Public Health, Thailand, Tel: +66 38784 006; E-mail: salakchit.c@dmsc.mail.go.th

Received September 09, 2014; Accepted September 27, 2014; Published October 03, 2014

Citation: Chutipongvivate S, Prompunjai Y, Neadruengsang W, Wangsiricharoen S (2014) Alternative Malaria Diagnostic Tools: Evaluation of Plasmodium falciparum Detection along Thailand's Border by Loop-Mediated Isothermal Amplification (LAMP) and Immunochromatographic Test (ICT). J Trop Dis 2: 147. doi: 10.4172/2329-891X.1000147

Copyright: () 2014 Chutipongvivate S, et al. This is an open-access article distributed under the terms of the Creative Commons Attribution License, which permits unrestricted use, distribution, and reproduction in any medium, provided the original author and source are credited. 
Citation: Chutipongvivate S, Prompunjai Y, Neadruengsang W, Wangsiricharoen S (2014) Alternative Malaria Diagnostic Tools: Evaluation of Plasmodium falciparum Detection along Thailand's Border by Loop-Mediated Isothermal Amplification (LAMP) and Immunochromatographic Test (ICT). J Trop Dis 2: 147. doi: 10.4172/2329-891X.1000147

\section{Subjects and Methods}

\section{Clinical sample}

The blood samples were collected from patients who came to malaria clinic during May to July 2014. One hundred and four of samples were obtained from patients who were diagnosed malaria positive by clinical diagnosis or subjected to suffering from malaria as observed from clinical history. EDTA blood was taken before patients were treated with anti-malarials. The template DNA was extracted from $200 \mu \mathrm{l}$ of EDTA blood using QIAamp DNA Blood Mini kits (QIAGEN GmbH, Hilden, Germany), according to the manufacturer's protocol. The hospitals in this study were closed to Thailand's border area. Three hospitals were in the province of Chiangmai, Mahongsorn and Kanchanaburi near Myanmar-Thailand border and two hospitals in the province of Trat and Sa Kaeo near the Cambodia-Thailand border. This study was performed using a protocol approved for medical research on human subjects, Department of Medical Sciences, Ministry of Public Health, Thailand.

\section{Microscopy}

Microscopy of thick and thin Giemsa-stained smears was considered the traditional standard method to detect malaria infection [17]. The analysis of the sample by microscopy was prepared by trained microscopists upon admission of the patient. Each smear was examined by two microscopists for the presence of parasites per 500 white blood cells counted and for the specie identification. This dependence on microscopist's expertise can be illustrated by the results of external quality control of the Malaria center, Ministry of Public Health, Thailand.

\section{Immunochromatographic Test (ICT)}

The ICT test was performed with the parasite lactate dehydrogease $(\mathrm{pLDH})$ antigen-based lateral flow test (DMSc Malaria Pf/PAN Rapid test, Thailand) used according to the manufacturer's instructions. The test detects $P$. falciparum specific and pan-specific antigens. Two trained readers examined the ICT, independently. A test was considered negative only if the internal control was visible. The result of an ICT was considered not valid if the internal control was not visible.

\section{Nested Polymerase Chain Reaction (Nested PCR)}

All samples were tested for genus Plasmodium, P. falciparum by nested PCR. The species-specific nucleotide sequences of the 18S rRNA genes were applied as described previously with slight modifications [18]. For the outer PCR, $1 \mu \mathrm{l}$ of template DNA was added to a $21 \mu \mathrm{l} \mathrm{PCR}$ mixture that consisted of $0.88 \mu \mathrm{M}$ each universal primer ( $\mathrm{P} 1$ forward and $\mathrm{P} 2$ reverse primer), $0.44 \mu \mathrm{M}$ deoxynucleoside triphosphate (10 $\mathrm{mM}$ each), $1,5 \mu \mathrm{M} \mathrm{MgCl} 2(25 \mathrm{mM}), 2.2 \mu \mathrm{M} 10 \mathrm{x}$ ImmoBuffer (100 $\mathrm{mM} \mathrm{NaCl}, 20 \mathrm{mM}$ Tris-HCl, $\mathrm{pH}$ 7.5, $0.1 \mathrm{mM}$ EDTA, $2 \mathrm{mM}$ DTT, 50\% Glycerol,stabilizers), 0.25 U IMMUNLASE DNA Polymerase (5 $\mathrm{U} / \mu \mathrm{l})$ and $14.85 \mu \mathrm{l}$ of distilled water. dNTP, $\mathrm{MgCl} 2$, ImmoBuffer and IMMUNLASE DNA polymerase were obtained from Bioline USA Inc. (Taunton, Ma, USA). The DNA amplification was carried out under the following conditions: $94^{\circ} \mathrm{C}$ for $10 \mathrm{~min}$ and then 35 cycles at $92^{\circ} \mathrm{C}$ for $30 \mathrm{~s}, 60^{\circ} \mathrm{C}$ for $1.5 \mathrm{~min}$, and $72^{\circ} \mathrm{C}$ for $1 \mathrm{~min}$, followed by a final extension at $72^{\circ} \mathrm{C}$ for $5 \mathrm{~min}$. The outer PCR product was diluted 40 -fold in sterile water. One microlitre of this solution was used in the second amplification. The inner PCR was performed at $94^{\circ} \mathrm{C}$ for $10 \mathrm{~min}$ and then $20 \mathrm{cycles}$ at $92^{\circ} \mathrm{C}$ for $30 \mathrm{~s}, 60^{\circ} \mathrm{C}$ for $1.5 \mathrm{~min}, 72^{\circ} \mathrm{C}$ for $1 \mathrm{~min}$, followed by a final extension at $72^{\circ} \mathrm{C}$ for 5 min with the $\mathrm{P} 1$ forward and reverse species-specific primer. The amplified products were visualized in $2.5 \%$ agarose gels stained with ethidium bromide. The expected band sizes were approximately $160 \mathrm{bp}$ for the outer primer PCR product and approximately $110 \mathrm{bp}$ for the inner primer PCR product.

\section{Loop-Mediated Isothermal Amplification (LAMP)}

All blood samples were tested by a primer set for Plasmodium DNA and a species-specific $P$. falciparum. The LAMP method was modified by previous study $[16,19]$. Modifications had to be applied as follows: For the LAMP reaction for genus Plasmodium, $1 \mu \mathrm{l}$ of template DNA was added to a $19 \mu \mathrm{l}$ LAMP mixture, containing $6.3 \mu \mathrm{l}$ of DW, $1.3 \mu \mathrm{l}$ of primer mix, $10.4 \mu \mathrm{l}$ of $2 \mathrm{x}$ Reaction LAMP buffer and $1 \mu \mathrm{l}$ of BstDNA-polymerase (BioLabs Inc., Ipswich, MA, USA). For P. falciparum slight modifications had to be applied. $1 \mu \mathrm{l}$ of Betain was added, the $2 \mathrm{x}$ Reaction LAMP buffer was adjusted and DW was reduced to $4.74 \mu \mathrm{l}$. The reactions were incubated at $65^{\circ} \mathrm{C}$ for $60 \mathrm{~min}$; the amplification was performed by water bath. All tubes were analysed by gel electrophoresis to assess the presence of the LAMP DNA product and stained with ethidium bromide (Promega, Madison, WI, USA).

\section{Statistical analysis}

The data was analyzed to calculate test performances and acceptable evaluation indices using nested PCR results as the reference standard. The indices measured were the number of true positives (TP), number of true negatives (TN), number of false positives (FP), and number of false negatives $(\mathrm{FN})$. Sensitivity was defined as $\mathrm{TP} /(\mathrm{TP}+\mathrm{FN})$, specificity as $\mathrm{TN} /(\mathrm{TN}+\mathrm{FP})$, positive predictive value $(\mathrm{PPV})$ as $\mathrm{TP} /(\mathrm{TP}+\mathrm{FP})$, and negative predictive value (NPV) as $\mathrm{TN} /(\mathrm{FN}+\mathrm{TN})$. The $95 \%$ confidence interval for sensitivity and specificity was calculated using MINITAB 14 software. For analysis of concordant results, Cohen's kappa statistics was used as a reference for two methods. The equation for $\kappa$ is $[\mathrm{P}(\mathrm{a})$ $\mathrm{P}(\mathrm{e})] /[1-\mathrm{P}(\mathrm{e})]$. If the methods are in complete agreement, $\kappa=1$.

\section{Results}

One hundred and four samples were tested by microscopy, ICT, LAMP and nested PCR. Nested PCR which was used as the reference method, was positive for $P$. falciparum in $71(68.27 \%)$ patients whereas 70 (67.31\%), 64 (61.54\%) and $70(67.31 \%)$ were positive by microscopy, ICT and LAMP respectively. The remaining was detected as negative. All of 33 nPCR negative samples were also negative by LAMP and ICT assay (specificity 100\%) while microscopy had one false positive (specificity 96.97\%).

This result indicated that microscopy gave both false negative and false positive (sensitivity $98.59 \%$. specificity $96.97 \%$ ). In this study, we evaluate LAMP and ICT for assessing a positive result. Neither of them produced any false positive results, translating into a specificity and positive predictive value of $100 \%$ (Table 1 ). The sensitivity (95\% CI)

\begin{tabular}{|c|c|c|c|c|c|c|c|c|c|c|c|c|}
\hline & Sen & $95 \% \mathrm{Cl}$ for sen & Spec & 95\% Cl for spec & PPV & 95\% Cl for PPV & NPV & $95 \% \mathrm{Cl}$ for NPV & $P(a)$ & $P(e)$ & Kappa (к) & $95 \%$ Cl for Kappa \\
\hline Mic & 98.59 & $(95.85-100.00)$ & 96.97 & $(91.12-100.00)$ & 98.59 & $(95.85-100.00)$ & 96.97 & $(91.12-100.00)$ & 0.9808 & 0.5668 & 0.9556 & $(89.47-100.00)$ \\
\hline ICT & 90.14 & $(83.21-97.08)$ & 100.00 & $(100.00-100.00)$ & 100.00 & $(100.00-100.00)$ & 82.50 & $(70.72-94.28)$ & 0.9327 & 0.5422 & 0.8530 & $(74.78-95.82)$ \\
\hline LAMP & 98.59 & $(95.85-100.00)$ & 100.00 & $(100.00-100.00)$ & 100.00 & $(100.00-100.00)$ & 97.06 & $(91.38-100.00)$ & 0.9904 & 0.5632 & 0.9780 & $(93.51-100.00)$ \\
\hline
\end{tabular}

Mic: Microscopy; ICT: Immunochromatography Test; LAMP: Loop-mediated Isothermal PCR; Sen: Sensitivity; spec: Specificity; PPV: Positive Predictive Value; NPV: Negative Predictive Value; $\mathrm{P}(\mathrm{a})$ : Percent Agreement; $\mathrm{P}(\mathrm{e})$ : Probability random agreement.

Table 1: Agreement, Sensitivity, Specificity, PPV and NPV of microscopy, ICT and LAMP for faciparum malaria versus gold standard nested PCR. 
Citation: Chutipongvivate S, Prompunjai Y, Neadruengsang W, Wangsiricharoen S (2014) Alternative Malaria Diagnostic Tools: Evaluation of Plasmodium falciparum Detection along Thailand's Border by Loop-Mediated Isothermal Amplification (LAMP) and Immunochromatographic Test (ICT). J Trop Dis 2: 147. doi: 10.4172/2329-891X.1000147

\begin{tabular}{|c|c|c|c|c|}
\hline \multirow{2}{*}{ Sen } & & Per dif & $\mathbf{9 5 \%}$ CI for per dif & P-value \\
\cline { 2 - 5 } & Mic vs ICT & 8.45 & $(0.99$ to 15.91) & 0.029 \\
\cline { 2 - 5 } & LAMP vs ICT & 8.45 & $(0.99$ to 15.91$)$ & 0.029 \\
\hline \multirow{2}{*}{ Spec } & Mic vs ICT & -3.03 & $(-8.88$ to 2.82$)$ & 0.314 \\
\cline { 2 - 5 } & LAMP vs ICT & 0.00 & & \\
\hline \multirow{2}{*}{ PPV } & Mic vs ICT & -1.41 & $(-4.15$ to 1.33$)$ & 0.341 \\
\cline { 2 - 5 } & LAMP vs ICT & 0.00 & & \\
\hline \multirow{2}{*}{ NPV } & Mic vs ICT & 14.47 & $(1.32$ to 27.62$)$ & 0.049 \\
\cline { 2 - 5 } & LAMP vs ICT & 14.56 & $(1.49$ to 27.63$)$ & 0.044 \\
\hline
\end{tabular}

Nested PCR was used as reference test. The P-value concerns the difference with the ICT.

Mic: Microscopy; ICT: Immunochromatography Test; LAMP: Loop-mediated Isothermal PCR; Sen: Sensitivity; spec: Specificity; PPV: Positive Predictive Value; NPV: Negative Predictive Value; Per dif: Percent difference.

Table 2: Comparison of LAMP and microscopy with ICT for faciparum malaria in Thailand's border area.

of the LAMP was comparable with ICT: $98.59 \%$ (95.8-100\%) versus 90.14\% (83.2-97.0\%: $\mathrm{P}=0.02$, Table 1).The negative predictive value ( $95 \%$ CI) of LAMP was $97.06 \%$ (91.38-100.00\%). The highest agreement with nested PCR was achieved with the LAMP $(99.04 \%, \kappa=0.98)$. The LAMP showed the highest negative predictive value and $100 \%$ positive predictive value comparing with ICT and microscopy (Table 1).

\section{Discussion}

The corner stone of malaria control is prompt diagnosis, which remains the basis for effective anti-malarial treatment. A rational therapy avoids non-target effects and saves costs on alternative drugs. Given the extent of multidrug-resistant $P$. falciparium infections and the resulting need for more expensive drugs unaffordable to resourcelimited countries, an accurate diagnosis is essential. In this study, we assessed which method, is best suited for diagnosis of clinical suspicion of malaria within a low or unstable endemic area. For this purpose, blood samples with the clinical symptoms of malaria from border hospitals were analyzed with microscope, ICT, LAMP and nested polymerase chain reaction (PCR) as the gold standard.

In Thailand, microscopy is the mainstay of malaria diagnosis. However, the sensitivity and specificity of microscopic technique varied depending on the blood staining, the amount of parasite density, quality of the microscope, well-trained competent microscopists and rigorous maintenance of effective quality control and quality assurance [20]. In addition, the impaired microscopy-based diagnosis in hospital laboratories is common [21]. In this study, microscopy gave both false positive and false negative. These errors seem like inherent limitations of microscopy for malaria diagnosis. Example of the false positive case by microscopy is misidentifying the stain granules and/or platelets superimposed on erythrocytes as the malarial parasite. Even among local laboratories with similar equipment, equal training and quality of essential laboratory supplies, abilities vary significantly [22,23].

Current ICT tests are manufactured with different target antigens. Histidine-Rich-Protein 2 (HRP-2) and pLDH are most common malaria antigens targeted and specific for $P$. Falciparum. HRP-2 tests gave $P$. falciparum sensitivity of $90 \%$ or more in clinical cases [24,25]. However, the sensitivity of $\mathrm{pLDH}$ assays was varied. Sensitivity for P. falciparum is excellent $(>95 \%)$ in some studies and poorer $(80 \%+)$ in the others [26,27]. In this study, ICT using pLDH assays showed the lowest value of sensitivity $(90.14 \%)$ which is a failure to correctly identify malaria infected person. Moreover, ICT gave a high rate of false negative comparing with LAMP. Several factors in manufacturing process as well as environmental conditions may affect ICT performance [25]. In addition, exposure of the test kit to high temperature during transport and storage is commonplace in tropical countries and can degrade the test and bias the result [20]. In this study, the ICT storage and transport conditions were controlled throughout the study, and the storage temperature was that recommended by the manufacture.

The recently described LAMP technique has the potential of combining the accuracy of molecular technique with low cost and simple technical requirements. To perform the test only water bath and gel electrophoresis are needed. Water bath commonly used in routine work and gel electrophoresis are not expensive and can be used in a laboratory of a rural border hospital. In this study, 104 blood samples from malaria endemic border Thai provinces were collected for comparative malaria diagnosis. These samples were diagnosed using microscopy, ICT, LAMP and nested PCR as the gold standard. Both LAMP and ICT showed specificity and positive predictive value of $100 \%$ but the LAMP showed higher sensitivity, PPV and NPV than ICT. Furthermore, LAMP gave the highest agreement with nested PCR. Although the use of simple techniques, together with common instruments, has the advantage that they can be deployed in a resourcelimited setting, a strictly separated area is needed to perform the test. Avoidance of contamination should have priority when conducting the assay, which can be obtained by changing gloves between every assay and strict separation of reagent. Accuracy of LAMP is sufficient to promote its use as a diagnostic tool because the test currently shows acceptably high rates of sensitivity and specificity. Furthermore, LAMP gave a low rate of false negative results which is particularly important to clinicians using diagnostic tests because failing to treat a true case of faciparum malaria may result in progression to a severe disease and death. This is a preliminary study. Hence, this method needs further study and validation using a larger sample size before it can be adopted for malaria diagnosis in the field. In conclusion, LAMP is a promising malaria diagnostic tool to enable molecular diagnosis of $P$. falciparum in settings with limited technical resources especially laboratories in hospital along border where malaria are endemic and unstable to progress towards malaria elimination in Thailand.

\section{Acknowledgement}

We are grateful for the help of many officials of Provincial Health Service, and Ministry of Public Health. Special thanks are extended to the staff of laboratory in province of Chiangmai, Mahongsorn, Kanchanaburi, Trat and Sa Kaeo for their cooperation.

\section{References}

1. Singh B, Daneshvar C (2013) Human infections and detection of Plasmodium knowlesi. Clin Microbiol Rev 26: 165-184.

2. Clark IA, Alleva LM, Mills AC, Cowden WB (2004) Pathogenesis of malaria and clinically similar conditions. Clin Microbiol Rev 17: 509-539, table of contents.

3. Hamer DH, Ndhlovu M, Zurovac D, Fox M, Yeboah-Antwi K, et al. (2007) Improved diagnostic testing and malaria treatment practices in Zambia. JAMA 297: 2227-2231.

4. World Malaria Report (2012) World Health Organization.

5. Malaria Control Programme in Thailand (2012) Ministry of Public Health.

6. Country Briefing: Eliminating malaria in Thailand (2013) University of California

7. Konchom S, Singhasivanon P, Kaewkungwal J, Chuprapawan S, Thimasarn K et al. (2005) Chronicle of malaria epidemics in Thailand, 1980-2000. Southeast Asian J Trop Med Public Health 36 Suppl 4: 64-67.

8. Containment of Malaria Multi-Drug Resistance on the Cambodia-Thailand Border (2007) World Health Organization.

9. Mwangi TW, Mohammed M, Dayo H, Snow RW, Marsh K (2005) Clinica algorithms for malaria diagnosis lack utility among people of different age groups. Trop Med Int Health 10: 530-536.

10. Ende J, Lodesani C, Angheben A, pharm TH, Sirima SB, et al. (2007) Does 
Citation: Chutipongvivate S, Prompunjai Y, Neadruengsang W, Wangsiricharoen S (2014) Alternative Malaria Diagnostic Tools: Evaluation of Plasmodium falciparum Detection along Thailand's Border by Loop-Mediated Isothermal Amplification (LAMP) and Immunochromatographic Test (ICT). J Trop Dis 2: 147. doi: 10.4172/2329-891X.1000147

the introduction of malaria antigen tests improve clinical care? Results from a randomized study in Burkina Faso. Trop Med Int Health 12:128.

11. Malaria Diagnostic testing. World Health Organization.

12. Toma H, Kobayashi J, Vannachone B, Arakawa T, Sato Y, et al. (2001) A field study on malaria prevalence in southeastern Laos by polymerase chain reaction assay. Am J Trop Med Hyg 64: 257-261.

13. Singh B, Bobogare A, Cox-Singh J, Snounou G, Abdullah MS, et al. (1999) A genus- and species-specific nested polymerase chain reaction malaria detection assay for epidemiologic studies. Am J Trop Med Hyg 60: 687-692.

14. Dong J, Olano JP, McBride JW, Walker DH (2008) Emerging pathogens: challenges and successes of molecular diagnostics. J Mol Diagn 10: 185-197.

15. Notomi T, Okayama H, Masubuchi H, Yonekawa T, Watanabe K, et al. (2000) Loop-mediated isothermal amplification of DNA. Nucleic Acids Res 28: E63.

16. Poon LL, Wong BW, Ma EH, Chan KH, Chow LM, et al. (2006) Sensitive and inexpensive molecular test for falciparum malaria: detecting Plasmodium falciparum DNA directly from heat-treated blood by loop-mediated isothermal amplification. Clin Chem 52: 303-306.

17. Milne LM, Kyi MS, Chiodini PL, Warhurst DC (1994) Accuracy of routine laboratory diagnosis of malaria in the United Kingdom. J Clin Pathol 47: 740 742.

18. Kimura K, Kanekob O, Liu Q, Zhou M, Kawamato F, et al. (1997) Identification of the four species of human malaria parasites by nested PCR that targets variant sequences in the small subunit rRNA gene. Parasitol int 46: 91-95.

19. Han ET, Watanabe R, Sattabongkot J, Khuntirat B, Sirichaisinthop J, et al. (2007) Detection of four Plasmodium species by genus- and species-specific loop-mediated isothermal amplification for clinical diagnosis. J Clin Microbio 45: 2521-2528.
20. Wongsrichanalai C, Barcus MJ, Muth S, Sutamihardja A, Wernsdorfer WH (2007) A review of malaria diagnostic tools: microscopy and rapid diagnostic test (RDT). Am J Trop Med Hyg 77: 119-127.

21. [No authors listed] (1988) Malaria diagnosis: memorandum from a WHO meeting. Bull World Health Organ 66: 575-594.

22. Durrhelm DN, Becker PJ, Bilinghurst K, Brink A (1997) Diagnostic disagreement-The lesson learnt from malaria diagnosis in Mpumalanga. S Afr Med J 87: 609-611.

23. Maguire JD, Lederman ER, Barcus MJ, O'Meara P, Jordon RG, et al. (2006) Production and Validation of durable, high quality standard malaria microscopy slides for teaching, testing and quality assurance during an era of declining diagnostic profiency. Malar J 5: 92.

24. Hopkins H, Kambale W, Kamya MR, Staedke SG, Dorsey G, et al. (2007) Comparison of HRP2- and pLDH-based rapid diagnostic tests for malaria with longitudinal follow-up in Kampala, Uganda. Am J Trop Med Hyg 76: 1092-1097.

25. Mboera LE, Fanello Cl, Malima RC, Talbert A, Fogliati $P$, et al. (2006) Comparison of the Paracheck-Pf test with microscopy, for the confirmation of Plasmodium falciparum malaria in Tanzania. Ann Trop Med Parasitol 100: 115122.

26. Iqbal J, Muneer A, Khalid N, Ahmed MA (2003) Performance of the OptiMAL test for malaria diagnosis among suspected malaria patients at the rural health centers. Am J Trop Med Hyg 68: 624-628.

27. Singh N, Valecha N, Nagpal AC, Mishra SS, Varma HS, et al. (2003) The hospital- and field-based performances of the OptiMAL test, for malaria diagnosis and treatment monitoring in central India. Ann Trop Med Parasitol 97: 5-13. 